\title{
Development of Advanced Biodevices Using Quantum Beam Microfabrication Technology
}

\author{
Tomoko G. Oyama ${ }^{\circledR}$, Atsushi Kimura, Naotsugu Nagasawa, Kotaro Oyama \\ and Mitsumasa Taguchi *(D)
}

\begin{abstract}
Department of Advanced Functional Materials Research, Takasaki Advanced Radiation Research Institute, Quantum Beam Science Research Directorate, National Institutes for Quantum and Radiological Science and Technology, Takasaki 370-1292, Japan; ohyama.tomoko@qst.go.jp (T.G.O.); kimura.atsushi@qst.go.jp (A.K.); nagasawa.naotsugu@qst.go.jp (N.N.); oyama.kotaro@qst.go.jp (K.O.)

* Correspondence: taguchi.mitsumasa@qst.go.jp; Tel.: +81-27-346-9386
\end{abstract}

\begin{abstract}
Biodevices with engineered micro- and nanostructures are strongly needed for advancements in medical technology such as regenerative medicine, drug discovery, diagnostic reagents, and drug delivery to secure high quality of life. The authors produced functional biocompatible plastics and hydrogels with physical and chemical properties and surface microscopic shapes that can be freely controlled in three dimensions during the production process using the superior properties of quantum beams. Nanostructures on a biocompatible poly(L-lactic acid) surface were fabricated using a focused ion beam. Soft hydrogels based on polysaccharides were micro-fabricated using a focused proton beam. Gelatin hydrogels were fabricated using $\gamma$-rays and electron beam, and their microstructures and stiffnesses were controlled for biological applications. HeLa cells proliferated three-dimensionally on the radiation-crosslinked gelatin hydrogels and, furthermore, their shapes can be controlled by the micro-fabricated surface of the hydrogel. Long-lasting hydrophilic concave structures were fabricated on the surface of silicone by radiation-induced crosslinking and oxidation. The demonstrated advanced biodevices have potential applications in three-dimensional cell culture, gene expression control, stem cell differentiation induction/suppression, cell aggregation into arbitrary shapes, tissue culture, and individual diagnosis in the medical field.
\end{abstract}

Keywords: biodevice; hydrogel; crosslinking; microfabrication; poly(L-lactic acid); protein; polydimethylsiloxane

\section{Introduction}

Quantum beams transfer their kinetic energy to target materials through ionization and excitation, and chemical reactions occur on the surface of and inside the materials via reactive species, such as electrons and radicals [1,2]. Typical chemical reactions induced on polymer materials are main chain scission, crosslinking, double bond formation, and oxidation. The branching ratio of these reactions can be controlled by an atmospheric condition, temperature, and state of the target materials, and also by dose, dose rate, and linear energy transfer (LET). The irradiated (modified) area and volumes are controlled by the beam energy and size from the $\mathrm{cm}$ to $\mathrm{nm}$ level.

Various functional polymer materials have been developed by radiation and commercialized [3-5]. Specifically, radiation crosslinking has a large advantage in that it can modify the materials at room temperature without chemicals. For example, polymers coating an electric wire are crosslinked by the radiation and their properties are held even at higher temperature [6]. These wires are applied in heat-resistant household appliances and automotive applications. Furthermore, heat-shrinkable 
tube, foamed polyethylene [7,8], high-purity ceramic fiber [9], fluorine polymer materials $[10,11]$, and others [12-14] have been developed for practical use.

In addition to hard plastic materials, soft materials, including hydrogels, have also been developed [15-18]. Hydrogel contains a large amount of solvent (water) inside a three-dimensional network structure, is a highly flexible material, and can exchange substances (solutes and moisture) with the outside. Hydrogels are particularly applicable to drug carriers, cosmetics, wound dressings, biodevices, sensors, and cell culture scaffolds.

So far, new nanotechnology materials with controlled physical and chemical properties and shapes have been developed as innovative tools by controlling the quantum beam-induced chemical reactions with high precision. We have been developing functional biodevices that are indispensable for advanced medical, diagnostic, and bio-research by controlling the spatial distribution of the chemical reactions of polymer materials using the quantum beam. In particular, beyond classical modification using ionizing radiations, we developed new uses of the quantum beam as a microfabrication tool, local modification/functionalization tool, and processing tool capable of simultaneous sterilization to create unique functional materials that are impossible to manufacture by other methods such as chemical reagent, heat, UV light, and plasma. This mini-review introduces four development examples of biocompatible plastics and gel materials for medical use using the quantum beam.

First, poly(L-lactic acid) (PLLA) has been widely used for various medical applications, such as surgical sutures, bone fixation materials, and cell culture scaffolds owing to its high biocompatibility, biodegradability, modulus, mechanical hardness, and transparency [19-22]. PLLA is a plastic with the melting temperature of approximately $180^{\circ} \mathrm{C}$, and these products are injection or extrusion molded. However, PLLA has the low heat stability i.e., $T_{\mathrm{g}}$, glass transition temperature, is about $60^{\circ} \mathrm{C}$ and poor chemical resistance, so conventional micro/nanofabrication techniques are not applicable to PLLA. For applications of PLLA to advanced biodevices, such as lab-on-a-chip, it is essential to develop both precise fabrication and functionalization techniques. We thus applied top-down processing using quantum beams to PLLA, particularly focused ion beam (FIB) [23]. FIB provides ion beams such as $\mathrm{Ga}^{+}, \mathrm{He}^{+}$, and $\mathrm{Ne}^{+}$with a diameter of several $\mathrm{nm}$ to hundreds of $\mathrm{nm}$ that scans on sample surfaces. Both elastic and inelastic collisions occur along the ion track. The elastic collisions displace atoms of the target samples and sputter from the sample surface. This sputtering can be used as a direct etching of the sample surfaces to get fine patterning without chemical treatment, irradiation mask, and mold. So, FIB direct etching has been applied for fabrication of arbitrary-shaped micro/nanostructures of various polymers [24-27]. FIB irradiation also induces radiation-induced chemical reactions in polymers, thus direct etching and chemical reactions such as chain scission and crosslinking can be combined for micro/nanofabrication of polymeric materials [28]. The damage cascade and energy deposition of FIB can be simulated using SRIM/TRIM code [29]. Additionally, PLLA surfaces should have a controlled amount of $C=C$, which influences the cell attachment [30].

Second, focused proton beam writing (PBW) has been used for microfabrication of inorganic materials $[31,32]$ and hard polymers [33-36] for decades. PBW is a novel technique that draws by a focused proton beam with an energy of the order of $\mathrm{MeV}$ on target materials [37]. PBW is a highly flexible processing technology that can fabricate precisely without a mask and has been widely used in the semiconductor field. Recently, biocompatible organic devices have been widely developed in the bio- and medical fields [38]. Cell behaviors, such as attachment, growth, gene expression, and differentiation, depend on the chemical and physical properties of the base materials, such as the stiffness, hydrophilicity, microstructure, and electronic charge $[39,40]$. Because hydrogel has stiffness and hydrophilicity similar to those of tissues in the mammalian body, it is expected to be applied as a biological scaffold material [41]. Radiation crosslinking is extensively used as a strong tool to produce functional materials without any toxic crosslinking reagents. The formations of polysaccharide hydrogels have been reported using electron beam and $\gamma$-ray irradiations [42-44]. Here, we have developed a new use of PVW to microfabricate polysaccharides, which is expected as new material for the next-generation three-dimensional biological microdevices [45]. 
Third, in vivo, cells are supported by a hydrogel of proteins and polysaccharides called the extracellular matrix (ECM). It has been reported that not only the chemical component but the elasticity and topographical characteristics of the ECM are substantial cues to modulate or control the cell function and fate that are critical for tissue formation, maintenance, regeneration, and repair [46,47]. The main composition of the ECM is collagen. The ECM has the elasticity of $\sim 1 \mathrm{kPa}$ to a few $100 \mathrm{kPa}$ and topographical features ranging from nanometers to micrometers. ECM-mimicking cell culture substrates are required for controlling cell function and fate as in vivo. However, synthetic polymers having a completely different composition from collagen have been used as artificial ECM [48]. Since gelatin is obtained from collagen and chemical composition is similar to collagen, gelatin hydrogel has attracted considerable attention as an artificial ECM. However, the sol-gel transition of gelatin occurs at around $37^{\circ} \mathrm{C}$ and gelatin physical-gel cannot be used for cell culture. In order to avoid melting and control the stiffness of the hydrogel, use of chemical crosslinkers such as formaldehyde and glutaraldehyde that alter cytocompatibility and biodegradability of native gelatin is required [49]. When irradiated as solid state, gelatin is predominantly decomposed by ionizing-radiations. On the other hand, gelatin can be crosslinked by radiation in the presence of water, i.e., in the solution state [50]. Mayer et al. focused on electron beam cross-linking technology and developed gelatin and collagen hydrogels [51-53]. The quantum beam cross-linking technology capable of gelation without crosslinking agent is attracting attention for use in regenerative medicine and drug discovery. We introduced radiation-crosslinked gelatin hydrogels that can reproduce elasticity- and topography-controlled ECM for advanced biological applications [54].

Finally, polydimethylsiloxane (PDMS) is widely used in lab-on-a-chip technologies, since it has good optical transparency, low autofluorescence, biocompatibility, and ease of molding [55-57]. However, its hydrophobicity, originating from the repeating dimethylsiloxane units, is a significant drawback for the biological applications. The water contact angle (WCA) of PDMS is greater than $100^{\circ}$, thus the surface is commonly hydrophilized by plasma irradiation. However, the user must treat PDMS by the plasma just before use because PDMS surfaces rapidly recover their hydrophobicity [58-61]. There is also a method using a proton beam for local property modification of PDMS [33,34,36]. However, this method is not suitable for the mass production. Technology development is eagerly needed that can make the PDMS surface hydrophilic in the long time and its mass processing to obtain stable and reliable lab-on-a-chips. We developed microwell arrays with stable hydrophilic concaves on PDMS using low energy electron beam to resolve the above issue [62].

\section{Results and Discussion}

\subsection{Micro/Nanopatterning of PLLA Using FIB Irradiation}

We applied FIB top-down processing to PLLA [23]. PLLA (Eco-Plastic U'z S-12 supplied by the Toyota Motor Corporation, $\mathrm{Mw}=112,000$, density $\left.=1.26 \mathrm{~g} / \mathrm{cm}^{3}\right)$ dissolved in chloroform $(<10 \mathrm{wt} \%)$ was spin-coated onto silicon wafers and dried under ambient conditions $\left(\sim 25^{\circ} \mathrm{C}\right)$. FIB irradiation of $30 \mathrm{keV} \mathrm{Ga}^{+}$ions was used (SMI 2050, Hitachi High-Tech Science, Tokyo, Japan). We simulated the damage cascade and energy deposition of FIB using SRIM/TRIM code [29]. The sputtering yields of carbon, hydrogen, and oxygen in PLLA simulated for $30 \mathrm{keV} \mathrm{Ga}^{+}$FIB irradiation were $\sim 0.39$ atoms/ion, $\sim 1.34$ atoms/ion, and $\sim 0.71$ atoms/ion, respectively. Figure 1 shows the simulated energy deposition in PLLA. The energy deposition range of $30 \mathrm{keV} \mathrm{Ga}^{+}$ions into PLLA is $80 \mathrm{~nm}$. The deposited energy is used for both ionization/excitation of PLLA and phonon production (heat).

We investigated the etching depths of a 1.5- $\mu \mathrm{m}$-thick PLLA using $30 \mathrm{keV} \mathrm{Ga}^{+} \mathrm{FIB}$ with different ion fluences and beam currents. We found that both higher ion fluence and beam current (flux) increased the fabricated depth and surface roughness. The heat produced by the FIB irradiation influences the etching speed and fabrication accuracy, because PLLA easily undergoes thermal deformation when above its $T_{\mathrm{g}}$. Additionally, the thermal stability of PLLA is lowered by the radiation-induced decomposition. For the precise micro/nanofabrication of PLLA, we should reduce the influence of 
heat by suppressing beam current and ion fluence, or by choosing a thinner sample and isolated small-area irradiation.

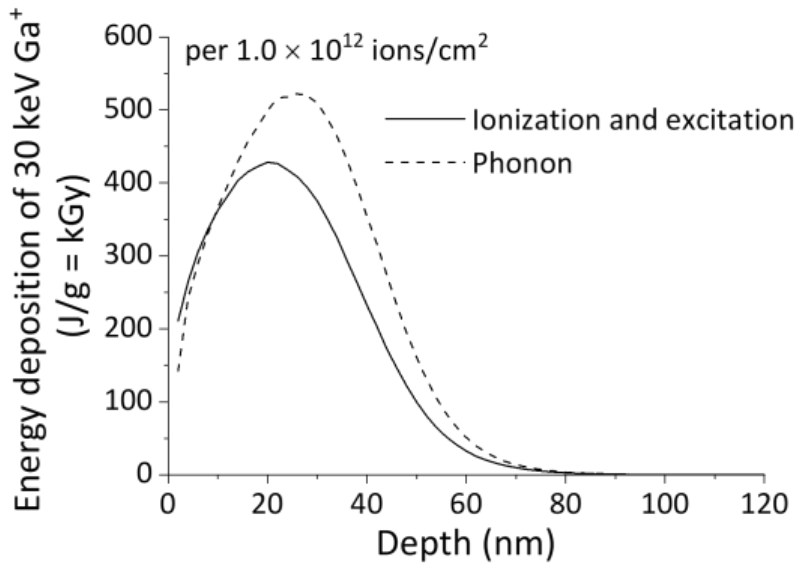

Figure 1. Energy deposition of $30 \mathrm{keV} \mathrm{Ga}^{+}$focused ion beam (FIB) in poly(L-lactic acid) (PLLA) per $1.0 \times 10^{12} \mathrm{ions} / \mathrm{cm}^{2}$.

The chemical states of the FIB-irradiated PLLA surfaces were investigated using micro-area X-ray photoelectron spectroscopy (XPS: PHI 5000 VersaProbe WS, ULVAC-PHI, Kanagawa, Japan). The obtained XPS spectra of $\mathrm{C} 1 \mathrm{~s}$ are shown in Figure 2. For the non-irradiated sample, there are three peaks at $284.8 \mathrm{eV}(\mathrm{C}-\mathrm{H}), 286.7 \mathrm{eV}(\mathrm{C}-\mathrm{O})$, and $288.8 \mathrm{eV}(\mathrm{O}=\mathrm{C}-\mathrm{O})$. After the FIB irradiation, the $\mathrm{C}-\mathrm{O}$ and $\mathrm{O}=\mathrm{C}-\mathrm{O}$ peaks decreased with the increase in the ion fluence, and two new peaks at $285.7 \mathrm{eV}(\mathrm{C}-\mathrm{OH})$ and $290.1 \mathrm{eV}(\mathrm{O}=\mathrm{C}-\mathrm{OH})$ appeared. These terminal groups generated by the irradiation indicate main chain scission of PLLA. We observed a significant peak shift from $284.8 \mathrm{eV}(\mathrm{C}-\mathrm{C} / \mathrm{C}-\mathrm{H})$ to $284.1 \mathrm{eV}$ $(\mathrm{C}=\mathrm{C})$, i.e., from $\mathrm{sp}^{3}$ to $\mathrm{sp}^{2}$. The $\mathrm{sp}^{3}$-to-sp $\mathrm{s}^{2}$ ratio became approximately $2: 3$ after irradiation with $1.0 \times 10^{15} \mathrm{ions} / \mathrm{cm}^{2}$. In addition, the O-to-C ratio was decreased by irradiation. These results show that the irradiated area is carbonized and changed into a $\mathrm{C}=\mathrm{C}$ bond-rich surface similar to diamond-like carbon (DLC) by physical sputtering and the desorption of decomposed fragments.

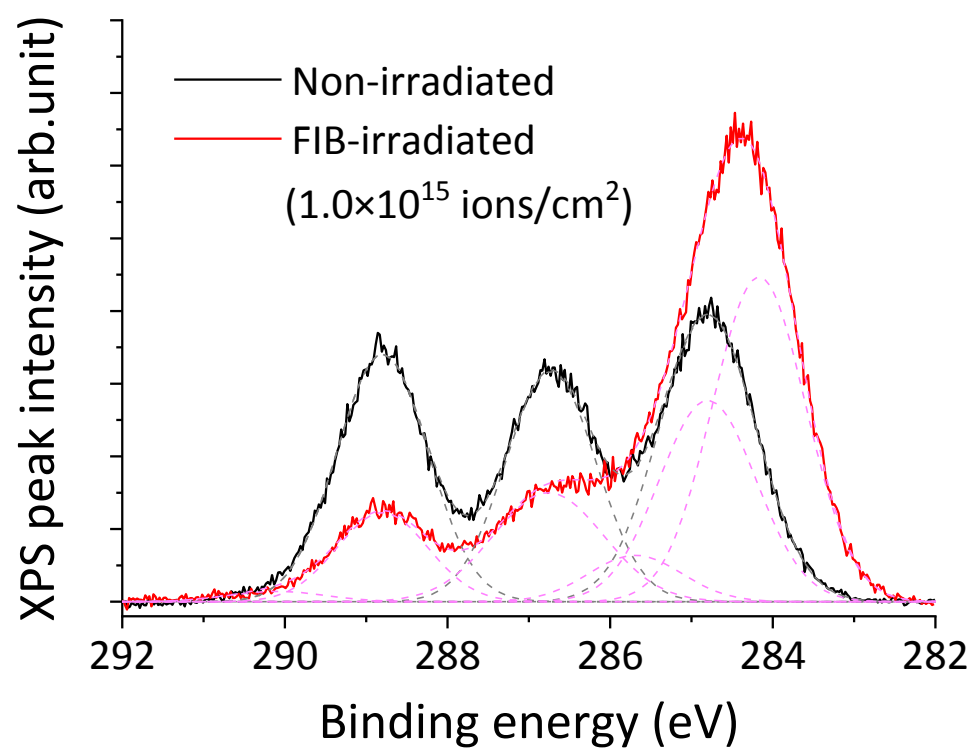

Figure 2. X-ray photoelectron spectroscopy (XPS) spectra of $\mathrm{C} 1 \mathrm{~s}$ in non-irradiated and focused ion beam (FIB)-irradiated $\left(1.0 \times 10^{15}\right.$ ions $\left./ \mathrm{cm}^{2}\right)$ poly(L-lactic acid) $($ PLLA). 
Figure 3 shows precise and arbitrary-shaped micro/nanostructures of PLLA observed with an atomic force microscope (SPI3800, Hitachi High-Tech Science, Tokyo, Japan) and a scanning electron microscope (S-3000N, HITACHI, Tokyo, Japan). By tuning the FIB irradiation conditions to avoid thermal deformation and debris, we obtained fine patterns such as $\phi 80-\mathrm{nm}$-through-holes and 60-nm-wide lines. Moreover, the surfaces of these micro/nanostructures of the PLLA have a controlled amount of $\mathrm{C}=\mathrm{C}$, which influences the cell attachment [30]. Micro-fabricated PLLAs by FIB direct etching are advanced micro/nanodevices applicable especially in the biology and medicine fields.
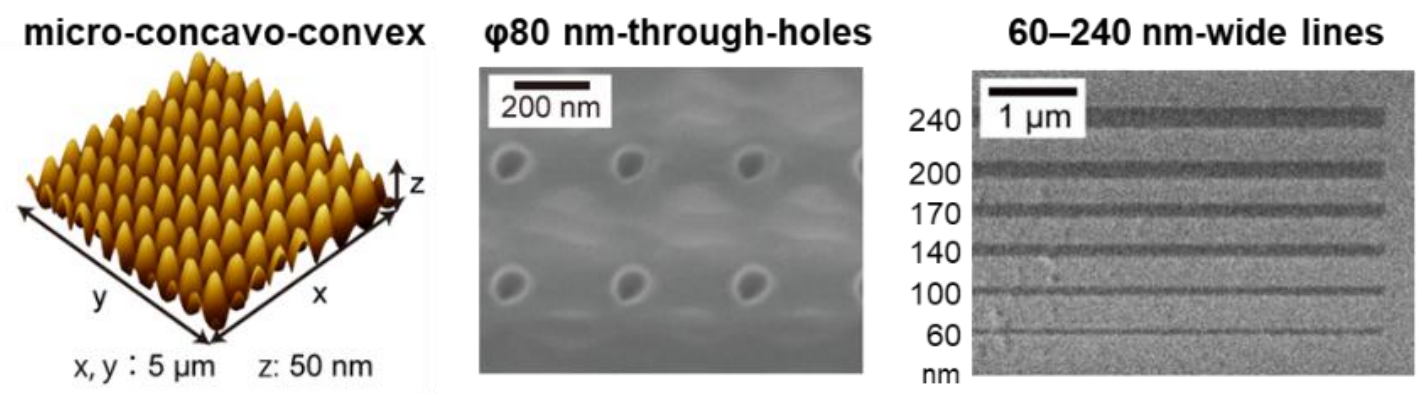

Figure 3. Precise and arbitrary-shaped micro/nanostructures of poly(L-lactic acid) (PLLA) obtained by focused ion beam (FIB) direct etching.

\subsection{Microfabricated Polysaccharide Hydrogels by Proton Beam Writing}

We used hydroxypropyl cellulose (HPC: NISSO HPC H type, Nippon Soda, Tokyo, Japan, a molar degree of substitution of 3) and sodium carboxymethyl cellulose (CMC: CMC DAICEL 1380, Daicel FineChem, Tokyo, Japan, a degree of substitution of 1.36) without further purification as base materials. These cellulose derivatives were dissolved in ultra-pure water at $30 \%$ for HPC and 50\% for CMC. Then the paste-like state samples were irradiated with a $3.0 \mathrm{MeV}$ focused proton microbeam under atmospheric pressure conditions [63]. Air gap between sample and the beam extraction window was set at $1 \mathrm{~mm}$ for easy installation/exchange of the sample. The beam spot size on the sample surface was estimated at approximately $12 \mu \mathrm{m}$ full width at half maximum (FWHM). The penetration depths of the protons were estimated using PHITS code [64] and were approximately $97.5 \mu \mathrm{m}$ and $87.5 \mu \mathrm{m}$ in the HPC and CMC samples, respectively. The proton beam current was controlled at about $10 \mathrm{pA}$, as measured with a Faraday cup set at just before the beam extraction window. The irradiation dose was set at $25 \mathrm{kGy}$ to $100 \mathrm{kGy}$. $2 \mathrm{MeV}$ electron beam irradiation was also conducted on the HPC and CMC paste samples as a reference. The $2 \mathrm{MeV}$ electron beam has enough penetration range in the sample at $1.2 \mathrm{~g} / \mathrm{cm}^{2}$.

By a careful washing, the samples with pure water after the proton irradiation, insoluble hydrogels, were obtained like electron beam irradiation. The gel fractions of the hydrogels were estimated as the weight ratio of the dried crosslinked hydrogel to that of base polymer before irradiation. Figure 4 shows the gel fractions increasing with the dose of the proton beam and the electron beam. The swelling of the obtained hydrogels was estimated from the increment weight of the swollen hydrogel from that of dried hydrogel by absorbing ultra-pure water. The swelling of the hydrogels produced by the proton beam were also the same as that by the electron beam. Proton and electron beams are categorized as a low-LET radiation, and the hydrogels are formed by reactions of hydroxyl $(\mathrm{OH})$ radical from water molecule produced by the indirect irradiation effect of the incident electrons. Proton and electron beams produce the hydrogel having the same gel fraction and swelling. However, it is difficult to evaluate the other physical properties, such as stiffness, tensile strength, and elongation, of the hydrogels produced by the proton beam because of the smaller size. The physical properties are considered the same as that obtained by the electron beam irradiation based on the formation mechanism of the hydrogel. 


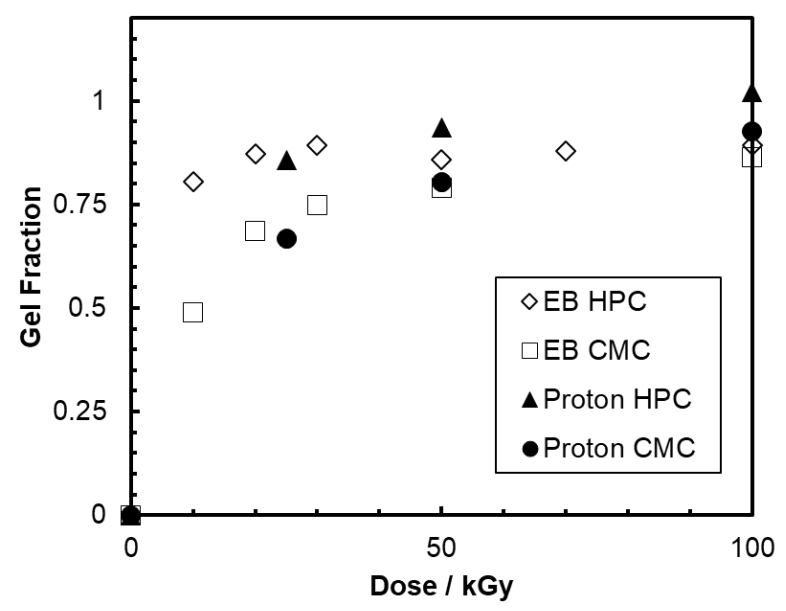

Figure 4. Gel fraction of hydroxypropyl cellulose (HPC) and sodium carboxymethyl cellulose (CMC) hydrogels obtained by $3.0 \mathrm{MeV}$ proton beam or $2 \mathrm{MeV}$ electron beam irradiation.

We successfully obtained the microstructured hydrogels with line-and-space, and hole patterns on polyethylene terephthalate film by the PBW technique. Figure 5 shows characteristic structures fabricated on the surface of HPC hydrogel. Here, we used line-and-space patterned hydrogel for the evaluation of the two-dimensional resolution of PBW. The produced square hydrogel was about $20 \mu \mathrm{m}$ larger than the irradiation plan. The deviation from the plan is considered to be induced by the scattering of the proton beam by the beam extraction window foil and air, and the swelling of the hydrogel. The stiffness of the microstructured hydrogel was easily controlled with the irradiation dose. We have extended the PBW technology to soft polymeric materials containing large amounts of water to be used as scaffold materials for three dimensional cell culture that mimics the in vivo environment required for regenerative medicine and drug discovery, or as a container for culturing small insects and observing their ecology.
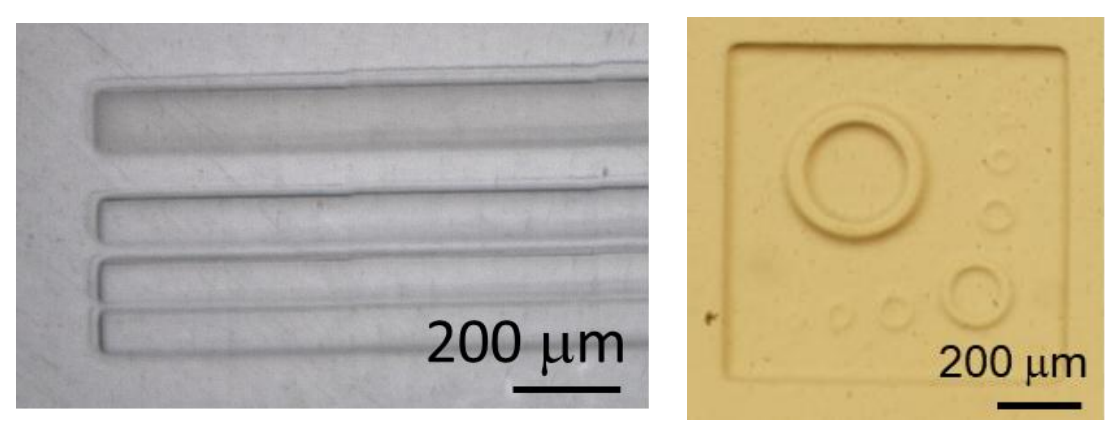

Figure 5. Swollen microfabricated hydroxypropyl cellulose (HPC) hydrogel produced by focused proton microbeam.

\subsection{Gelatin Hydrogels for Mimicking In Vivo Extracellular Matrix}

We introduce radiation-crosslinked gelatin hydrogels that can mimic chemical and physical properties of native ECM [54]. We prepared $10 \mathrm{wt} \%$ gelatin (from porcine skin, Type A, G1890, Sigma Aldrich, Tokyo, Japan) dissolved in ultra-pure water at $50{ }^{\circ} \mathrm{C}$ for $30 \mathrm{~min}$. The solution was poured into cell culture dishes (Iwaki 1000-035, AGC Techno Glass, Shizuoka, Japan), and stored overnight at $20^{\circ} \mathrm{C}$. Gelatin underwent physical gelation during the storage. The samples were irradiated with ${ }^{60} \mathrm{Co} \gamma$-rays or $2 \mathrm{MeV}$ electron beam. These simple procedures can change the gelatin solution into radiation-crosslinked hydrogels that do not melt even at $50{ }^{\circ} \mathrm{C}$. In addition, the irradiation not only induces crosslinking but also sterilizes the samples. 
The stiffness of the radiation-crosslinked gelatin hydrogels can be controlled by choosing the irradiation dose. As shown in Figure 6, the compressive modulus of the hydrogel can be tuned within a wide range from $5-500 \mathrm{kPa}$, which is the same range as the compressive modulus of the soft tissue. Moreover, the surfaces of the hydrogels can be precisely microfabricated by applying quantum beam nanoimprint lithography (QB-NIL). QB-NIL is a technique that uses radiation-crosslinking instead of photo-crosslinking (UV-nanoimprint) or heat (thermal-nanoimprint), thus the technique is suitable for micro/nanofabrication of biomaterials that cannot be heated or mixed with cytotoxic photo-crosslinkers/initiators. After the irradiation of gelatin solution covered with a patterned mold, the microfabricated hydrogels are obtained.

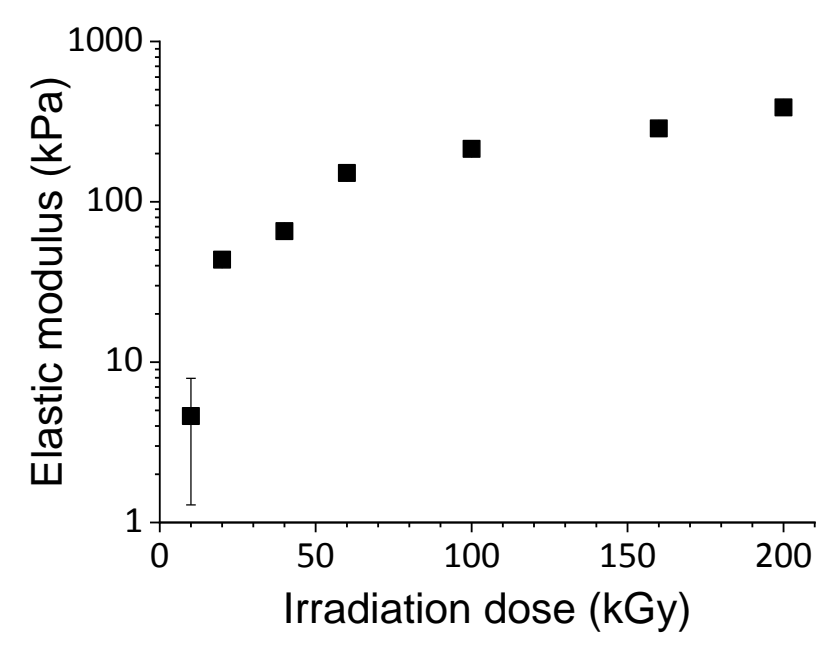

Figure 6. Elastic modulus of the radiation-crosslinked gelatin hydrogels.

We obtained radiation-crosslinked gelatin hydrogels with variable stiffness and surface micropatterns that can mimic native ECM chemically and physically. We cultured HeLa cells (RCB0007, BioResource Center, RIKEN, Ibaraki, Japan) in Minimum Essential Eagle's Medium (M5650, Sigma-Aldrich) supplemented with 10\% fetal bovine serum (SH30910.03, GE Healthcare Japan, Tokyo, Japan), $100 \mathrm{U} / \mathrm{mL}$ penicillin, $100 \mu \mathrm{g} / \mathrm{mL}$ streptomycin (15,140-122, Thermo Fisher Scientific, Tokyo, Japan), and 2 mM L-glutamine (10,378,016, Thermo Fisher Scientific, Tokyo, Japan). HeLa cells on the hydrogel were observed with an inverted microscope (IX70, Olympus, Tokyo Japan). Figure 7 shows HeLa cells (derived from cervical cancer) cultured on conventional polystyrene (stiffness: $>1 \mathrm{GPa}$ ) dish and our gelatin hydrogel with a stiffness of $\sim 10 \mathrm{kPa}$. The cellular morphologies are completely different from each other; the cells spread flat on the polystyrene dish but form aggregates (spheroids) on the gelatin hydrogel. In addition, the spheroids partially infiltrated the hydrogel. The cancer cells cultured on the gelatin hydrogels can be used as a "tumor model" to reproduce cell responses in vivo. We have investigated various cell responses on our hydrogels and found that cell functions were tuned by the stiffness of the hydrogels. Moreover, the micropatterns on the hydrogels can control the cell morphology as shown in Figure 7. The radiation-crosslinked gelatin hydrogels have various advantages in addition to its ECM-like chemical and physical properties. They can control cell functions by their stiffness and micropatterns without adding any chemical reagent; they can be directly transferred into the body without peeling the cultured cells; they are sterilized during their production process; and their mass production is easily realized in existing commercial radiation facilities used for sterilization. The developed radiation-crosslinking method has contributed to the creation of scaffold materials that can be used as next-generation cell culture substrates in tissue engineering and regenerative medicine. 
Polystyrene dish

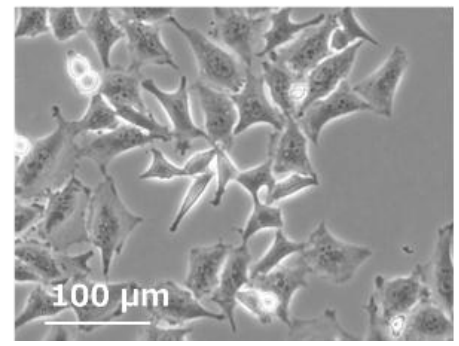

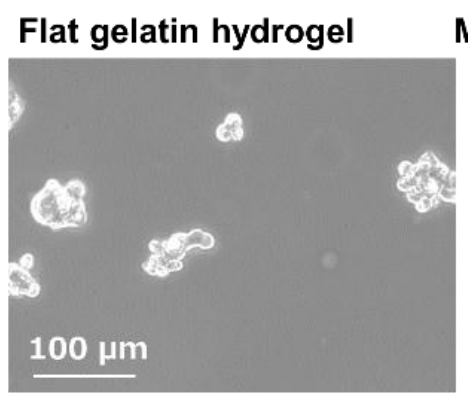

Micropatterned gelatin hydrogel

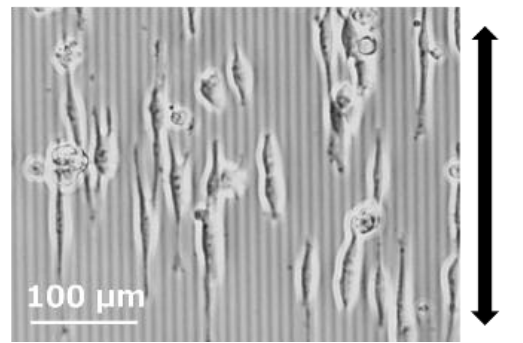

Figure 7. HeLa cell responses on polystyrene dish, flat gelatin hydrogel ( 10 kPa), and micropatterned gelatin hydrogel ( $5 \mu \mathrm{m}$-line-and space).

\subsection{Long-Lasting Hydrophilic Polydimethylsiloxane (PDMS) Microwell Arrays}

We propose a single-step fabrication method for long-lasting hydrophilic concaves on PDMS surfaces using low-energy electron beam (LE-EB) which is generated from a table-top accelerator (Figure 8) [62]. A mixture of the precursor SIM-260 and curing agent CAT-260 (both from Shin-Etsu Chemical, Tokyo, Japan) was poured on a Si substrate and heated at $150{ }^{\circ} \mathrm{C}$ for $30 \mathrm{~min}$. After the prepared PDMS films were peeled off from the substrate, we irradiated with LE-EBs at the energy of $55-90 \mathrm{kV}$. The energy deposition ranges of 55-90 kV LE-EBs in PDMS are $\sim 40-110 \mu \mathrm{m}$, and they are much deeper than that of plasma ( $<$ a few hundred $\mathrm{nm}$ ).
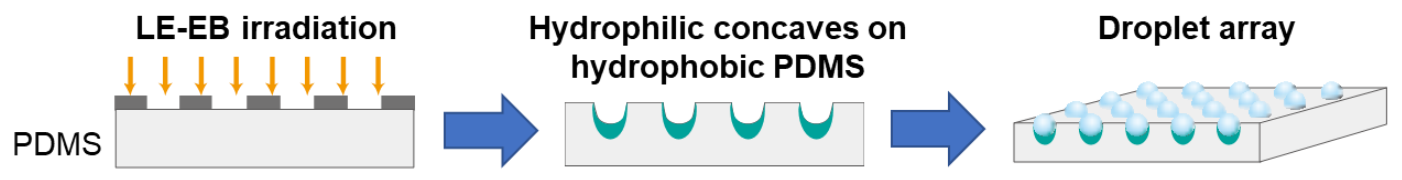

Figure 8. Proposed single-step fabrication method for obtaining hydrophilic concave patterns on hydrophobic polydimethylsiloxane (PDMS).

The hydrophilicity of the samples was evaluated by dropping ultra-pure water ( $2 \mu \mathrm{L}$, Millipore) onto the PDMS surfaces. The static WCAs were measured within $1 \mathrm{~h}$ after LE-EB irradiation using a contact angle meter (FACE, CA-V, Kyowa Interface Science, Saitama, Japan). The WCA of PDMS surface was decreased by LE-EB irradiation $(55 \mathrm{kV}, 330 \mathrm{kGy} / \mathrm{s})$ in air. The WCA changed from $\sim 103^{\circ}$ to $\sim 60^{\circ}$ after the irradiation of $10 \mathrm{MGy}$, and to $40^{\circ}$ for the irradiation doses above $15 \mathrm{MGy}$ (Figure $9 \mathrm{a}$ ). Furthermore, a concave pattern on the PDMS surface was fabricated by the LE-EB irradiation through patterned masks. The depth of the concave features determined from micrographs of cross-sections was dozens of micrometers.
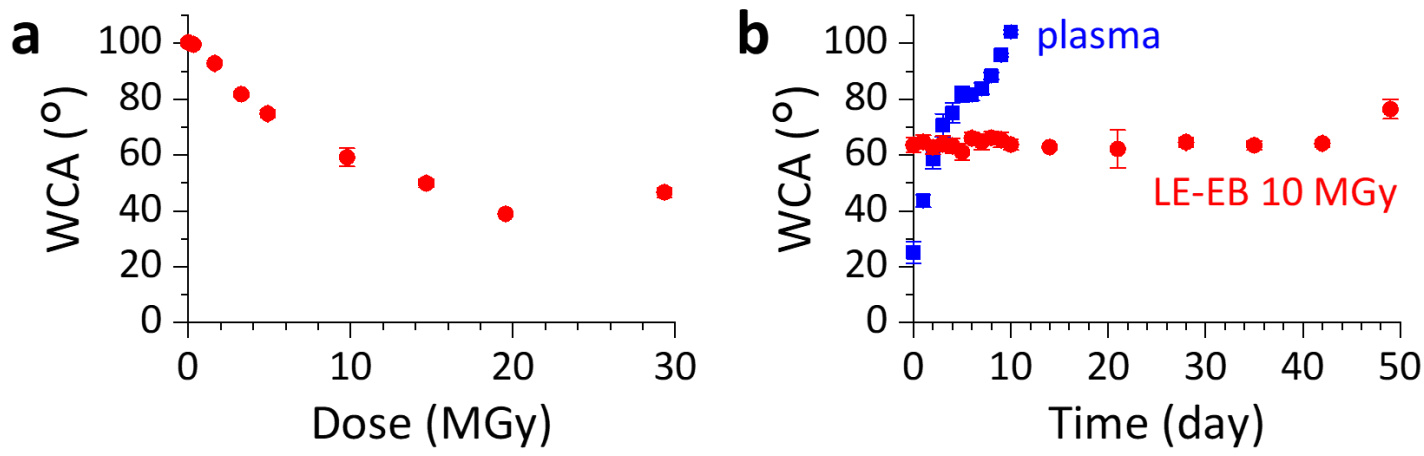

Figure 9. (a) Water contact angle change of low energy electron beam (LE-EB)-irradiated polydimethylsiloxane (PDMS) as a function of storage time in ultra-pure water at room temperature (RT). (b) Water contact angles of LE-EB-irradiated and plasma-irradiated (120 s) PDMS as a function of storage time in cell culture medium at $37^{\circ} \mathrm{C}$. 
We investigated the chemical changes of PDMS induced by LE-EB by Fourier-transform infrared spectroscopy (FT-IR: Nicolet iN10 MX, Thermo Fisher Scientific, Tokyo, Japan) and XPS (PHI5000 VersaProbe II, ULVAC-PHI, Kanagawa, Tokyo). The two-dimensional FT-IR chemical imaging for a cross-section of a 10 MGy-LE-EB-irradiated PDMS showed that peaks related to $-\mathrm{CH}_{3}$ stretching and bending $\left(2964,2904,1412\right.$, and $\left.1260 \mathrm{~cm}^{-1}\right)$ decreased to a depth of $\sim 40 \mu \mathrm{m}$ after LE-EB irradiation. Simultaneously, a broad peak appeared around $3400 \mathrm{~cm}^{-1}$ that is assigned to $-\mathrm{OH}$ stretching. These results show that the hydrophobic methyl groups in PDMS are decomposed and a hydrophilic layer as thick as the energy deposition range of LE-EB $(\sim 40 \mu \mathrm{m})$ was produced by the irradiation. From the XPS measurement, we found that the original peak of $\mathrm{Si}(-\mathrm{O})_{2}$ at $102 \mathrm{eV}$ shifted to $\mathrm{Si}(-\mathrm{O})_{3}(103 \mathrm{eV})$ and $\mathrm{Si}(-\mathrm{O})_{4}(104 \mathrm{eV})$.,

Both plasma and LE-EB decompose the hydrophobic methyl group and produce hydrophilic $\mathrm{Si}-\mathrm{OH}$ (silanol) and crosslinked SiOx-rich structure. The major difference between LE-EB and plasma is the durability of the hydrophilicity, which is originated from the different thickness of hydrophilized layer. Remarkably, the WCA of LE-EB-irradiated PDMS keeps $<75^{\circ}$ for more than a month storage in cell culture condition even after repeated drying for WCA measurement (Figure 9b), and 10 months in ultra-pure water at room temperature $\left(\mathrm{RT}, \sim 22^{\circ} \mathrm{C}\right)$. The hydrophilic SiOx-rich layer generated as thick as $40 \mu \mathrm{m}$ prolonged hydrophilicity. Moreover, the irradiated area compacted through the conversion to the $\mathrm{SiO}_{\mathrm{x}}$-rich inorganic phase forms dozens- $\mu \mathrm{m}$-deep concaves.

The most promising applications of concave features with the surfaces of durable hydrophilicity in PDMS is in cell culture. We demonstrated single-cell trapping in a microwell array chip (aperture: 35 $\mu \mathrm{m}$ square, depth: $30 \mu \mathrm{m}$ ), which was fabricated by $20 \mathrm{MGy}$ irradiation of LE-EB. The 3T3-Swiss albino mouse embryo fibroblast cells (RCB1642, RIKEN BRC Cell Bank, Ibaraki, Japan) were seeded on the chip. The bright-field images were obtained with an inverted microscope (IX70, Olympus) with a digital camera (AdvanVision), and visualized the cells stained with calcein-AM using NIBA mirror units (Olympus). The bright-field images were merged with the fluorescence images to create composite images using ImageJ software (National Institutes of Health). After $2 \mathrm{~h}$ incubation, the non-adherent cells were removed by washing the chip with cell-culture medium. The cells favorably adhered to the hydrophilic surfaces of the microwells, and single-cell-level trapping was achieved as shown in Figure 10.

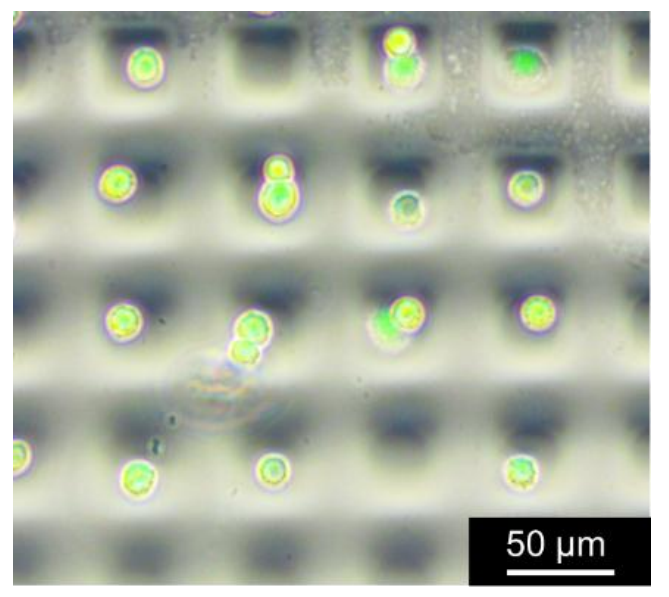

Figure 10. 3T3 cells trapped in a $35 \mu \mathrm{m}$ square microwell array chip.

Our reagent-free method does not affect the biocompatibility of PDMS and provides local hydrophilization within the wells/channels. This single-step fabrication of PDMS is a state-of-the-art technology that makes the most of the properties of low energy electron beam and contributes to the development of lab-on-a-chip technologies, such as high-throughput single-cell analyses for diagnosis, drug screening, and stem cell biology. 


\section{Conclusions}

We developed biocompatible functional materials using the micro/nano fabrication technique by controlling the quantum beam reaction qualitatively or spatially. Biocompatible PLLA, polysaccharide, gelatin, and PDMS having fine structures could capture cells individually or control cell shape, movement, and aggregations. Thus, biodevices created by the quantum beams are expected to greatly contribute not only to basic biological research but regenerative medicine, drug discovery, and individual diagnosis in the advanced medical field.

Author Contributions: All authors have read and agree to the published version of the manuscript. M.T. wrote original draft of Sections 1 and 3, T.G.O., N.N. Section 2.1, N.N., A.K. Section 2.2, T.G.O., A. K., K.O. Section 2.3, T.G.O. Section 2.4. Review and Editing, M.T.

Funding: This study was partially supported by Grant-in-Aid for JSPS Fellows 24-9069 (T.G.O), JSPS Grant-in-Aid for Young Scientists (B) 26790070 (T.G.O.), JSPS KAKENHI grants JP26790070 (T.G.O.), JP18K18390(T.G.O.), 19K12653 (A.K.), JP16K05927(N.N.).

Acknowledgments: We sincerely appreciate Prof. Seiichi Tagawa, Prof. Masakazu Washio, Dr. Akihiro Oshima, Ms. Ryoko Mezaki. Dr. Akira Idesaki, Dr. Michiyo Suzuki, and Mr. Akihiko Shimada., because the development of the advanced medical devices stated above could not have been achieved without them.

Conflicts of Interest: The authors declare no conflict of interest.

\section{References}

1. Wu, G.; Zhai, M.; Wang, M. (Eds.) Radiation Technology for Advanced Materials: From Basic to Modern Applications; Academic Press: Washington, DC, USA, 2019. [CrossRef]

2. Kumar, V.; Chaudhary, B.; Sharma, V.; Verma, K. (Eds.) Radiation Effects in Polymeric Materials; Springer: Cham, Switzerland, 2019. [CrossRef]

3. Makuuchi, K.; Cheng, S. Radiation Processing of Polymer Materials and Its Industrial Applications; John Wiley \& Sons: Hoboken, NJ, USA, 2012. [CrossRef]

4. Clough, R.L. High-energy radiation and polymers: A review of commercial processes and emerging applications. Nucl. Instrum. Methods Phys. Res. B 2001, 185, 8-33. [CrossRef]

5. Drobny, J.G. (Ed.) Ionizing Radiation and Polymers, Principles, Technology and Applications; Elsevier: Amsterdam, The Netherlands, 2013. [CrossRef]

6. Kemmotsu, T.; Okada, M.; Ono, T. Improvement of the surface of polyethylene foamed sheet by irradiation. Radiat. Phys. Chem. 1993, 42, 97-100. [CrossRef]

7. Cardoso, E.C.L.; Lugão, A.B.; Andrade, E.; Silva, L.G. Crosslinked polyethylene foams, via EB radiation. Radiat. Phys. Chem. 1998, 52, 197-200. [CrossRef]

8. Chenguang, Y.; Zhe, X.; Mingxing, Z.; Quan, Z.; Mouhua, W.; Guozhong, W. Supercritical $\mathrm{CO}_{2}$ foaming of radiation crosslinked polypropylene/high-density polyethylene blend: Cell structure and tensile property. Radiat. Phys. Chem. 2017, 141, 276-283. [CrossRef]

9. Ichikawa, H. Development of high performance $\mathrm{SiC}$ fibers derived from polycarbosilane using electron beam irradiation curing-A Review. J. Ceram. Soc. Jpn. 2006, 114, 455-460. [CrossRef]

10. Kobayashi, A.; Oshima, A.; Okubo, S.; Tsubokura, H.; Takahashi, T.; Oyama, T.G.; Tagawa, S.; Washio, M. Thermal and radiation process for nano-/micro-fabrication of crosslinked PTFE. Nucl. Instrum. Methods Phys. Res. B. 2013, 295, 76-80. [CrossRef]

11. Oshima, A.; Tabata, Y.; Kudoh, H.; Seguchi, T. Radiation induced crosslinking of polytetrafluoroethylene. Radiat. Phys. Chem. 1995, 45, 269-273. [CrossRef]

12. Wang, Y.; Qiu, J.; Peng, J.; Li, J.; Zhai, M. One-step radiation synthesis of gel polymer electrolytes with high ionic conductivity for lithium-ion batteries. J. Mater. Chem. A 2017, 5, 12393-12399. [CrossRef]

13. Cui, Z.; Bahry, T.; Dazzi, A.; Bui, T.-T.; Goubard, F.; Remita, S. Conducting polymers synthesized by $\gamma$-radiolysis in very acidic aqueous medium. Radiat. Phys. Chem. 2019, 159, 47-56. [CrossRef]

14. Shinyama, K. Influence of electron beam irradiation on electrical insulating properties of PLA with soft resin added. Polymers 2018, 10, 898. [CrossRef]

15. Rosiak, J.M.; Ulański, P.; Pajewski, L.A.; Yoshii, F.; Makuuchi, K. Radiation formation of hydrogels for biomedical purposes. Some remarks and comments. Radiat. Phys. Chem. 1995, 46, 161-168. [CrossRef] 
16. Yoshii, F.; Zhanshan, Y.; Isobe, K.; Shinozaki, K.; Makuuchi, K. Electron beam crosslinked PEO and PEO/PVA hydrogels for wound dressing. Radiat. Phys. Chem. 1999, 55, 133-138. [CrossRef]

17. Bhuyan, M.M.; Dafader, N.C.; Hara, K.; Okabe, H.; Hidaka, Y.; Rahman, M.M.; Khan, M.M.R.; Rahman, N. Synthesis of potato starch-acrylic-acid hydrogels by gamma radiation and their application in dye adsorption. Int. J. Polym. Sci. 2016, 9867859. [CrossRef]

18. Lugao, A.B.; Malmonge, S.M. Use of radiation in the production of hydrogels. Nucl. Instrum. Methods Phys. Res. B 2001, 185, 37-42. [CrossRef]

19. Garlotta, D. A literature review of poly (lactic acid). J. Polym. Environ. 2001, 9, 63-84. [CrossRef]

20. Nair, L.S.; Laurencin, C.T. Biodegradable polymers as biomaterials. Prog. Polym. Sci. 2007, 32, 762-798. [CrossRef]

21. Ju, J.; Peng, X.; Huang, K.; Li, L.; Liu, X.; Chitrakar, C.; Changf, L.; Gu, Z.; Kuangab, T. High-performance porous PLLA-based scaffolds for bone tissue engineering: Preparation, characterization, and in vitro and in vivo evaluation. Polymer 2019, 180, 121707. [CrossRef]

22. Yao, J.; Chen, Y.; Li, W.; Chen, X.; Fan, X. Fabrication and characterization of electrospun PLLA/PANI/TSA fibers. RSC Adv. 2019, 9, 5610-5619. [CrossRef]

23. Oyama, T.G.; Hinata, T.; Nagasawa, N.; Oshima, A.; Washio, M.; Tagawa, S.; Taguchi, M. Micro/nanofabrication of poly(L-lactic acid) using focused ion beam direct etching. Appl. Phys. Lett. 2013, 103, 163105. [CrossRef]

24. Miyoshi, N.; Oshima, A.; Urakawa, T.; Fukutake, N.; Nagai, H.; Gowa, T.; Takasawa, Y.; Takahashi, T.; Numata, Y.; Katoh, T.; et al. Nano- and micro-fabrication of perfluorinated polymers using quantum beam technology. Radiat. Phys. Chem. 2011, 80, 230-235. [CrossRef]

25. Fukutake, N.; Miyoshi, N.; Takasawa, Y.; Urakawa, T.; Gowa, T.; Okamoto, K.; Oshima, A.; Tagawa, S.; Washio, M. Micro- and nano-scale fabrication of fluorinated polymers by direct etching using focused ion beam. Jpn. J. Appl. Phys. 2010, 49, 065201. [CrossRef]

26. Okubo, S.; Takahashi, T.; Takasawa, Y.; Gowa, T.; Sasaki, T.; Nagasawa, N.; Tamada, M.; Oshima, A.; Tagawa, S.; Washio, M. Micro-fabrication of biodegradable polymers using focused ion beam. J. Photopolym. Sci. Technol. 2010, 23, 393-397. [CrossRef]

27. Oshima, A.; Okubo, S.; Oyama, T.G.; Washio, M.; Tagawa, S. Nano- and micro-fabrications of polystyrene having atactic and syndiotactic structures using focused ion beams lithography. Radiat. Phys. Chem. 2012, 81, 584-588. [CrossRef]

28. Oyama, T.G.; Oshima, A.; Washio, M.; Tagawa, S. Fabrication of nanobeads from nanocups by controlling scission/crosslinking in organic polymer materials. Nanotechnology 2012, 23, 495307. [CrossRef]

29. Ziegler, F.; Ziegler, M.D.; Biersack, J.P. SRIM-The stopping and range of ions in matter. Nucl. Instrum. Methods Phys. Res. B 2010, 268, 1818-1823. [CrossRef]

30. Tanaka, T.; Suzuki, Y.; Tsuchida, K.; Yajima, H. Improvement of cell attachment capabilities of poly-L-lactic acid films by modification of surface properties with ion-beam irradiation. Surf. Coat. Tech. 2013, 218, 162-166. [CrossRef]

31. van Kan, J.A.; Malar, P.; Wang, Y.H. Resist materials for proton beam writing: A review. Appl. Surf. Sci. 2014, 310, 100-111. [CrossRef]

32. Jin, H.; Turaga, S.P.; Vanga, S.K.; Bettiol, A.A. Single-mode light guiding in diamond waveguides directly written by a focused proton beam. Opt. Lett. 2018, 43, 2648-2651. [CrossRef]

33. Kaneko, Y.; Hayashi, H.; Ishii, Y.; Kada, W.; Nishikawa, H. Refractive index change and thermo-optic effect in polydimethylsiloxane nanocomposites with oxide nanoparticles induced by proton beam writing. Nucl. Instrum. Methods B 2019, 459, 94-97. [CrossRef]

34. Huszank, R.; Rajta, I.; Cserháti, C. Proton beam lithography in negative tone liquid phase PDMS polymer resist. Nucl. Instrum. Methods B 2015, 348, 213-217. [CrossRef]

35. Huszank, R.; Szilágyi, E.; Szoboszlai, Z.; Szikszaia, Z. Investigation of chemical changes in PMMA induced by 1.6 MeV He+ irradiation by ion beam analytical methods (RBS-ERDA) and infrared spectroscopy (ATR-FTIR). Nucl. Instrum. Methods B 2019, 450, 364-368. [CrossRef]

36. Huszank, R.; Bonyár, A.; Kámán, J.; Furua, E. Wide range control in the elastic properties of PDMS polymer by ion beam (H+) irradiation. Polym. Degrad. Stab. 2018, 152, 253-258. [CrossRef]

37. Watt, F.; Breese, M.B.H.; Bettiol, A.A.; van Kan, J.A. Proton beam writing. Mater. Today 2007, 10, $20-29$. [CrossRef] 
38. Liu, H.; Jian, R.; Chen, H.; Tian, X.; Sun, C.; Zhu, J. Application of Biodegradable and Biocompatible Nanocomposites in Electronics: Current Status and Future Directions. Nanomaterials 2019, 9, 950. [CrossRef] [PubMed]

39. Dowling, D.P.; Miller, I.S.; Ardhaoui, M.; Gallagher, W.M. Effect of surface wettability and topography on the adhesion of osteosarcoma cells on plasma-modified polystyrene. J. Biomatter. Appl. 2011, 26, 327-347. [CrossRef]

40. Engler, A.J.; Sen, S.; Sweeney, H.L.; Discher, D.E. Matrix elasticity directs stem cell lineage specification. Cell 2006, 126, 677-689. [CrossRef] [PubMed]

41. Discher, D.E.; Mooney, D.J.; Zandstra, P.W. Growth factors, matrices, and forces combine and control stem cells. Science 2009, 324, 1673-1677. [CrossRef] [PubMed]

42. Fei, B.; Wach, R.A.; Mitomo, H.; Yoshii, F.; Kume, T. Hydrogel of biodegradable cellulose derivatives. I. Radiation-induced crosslinking of CMC. J. Appl. Polym. Sci. 2000, 78, 278-283. [CrossRef]

43. Wach, R.A.; Mitomo, H.; Nagasawa, N.; Yoshii, F. Radiation crosslinking of carboxymethylcellulose of various degree of substitution at high concentration in aqueous solutions of natural $\mathrm{pH}$. Radiat. Phys. Chem. 2003, 68, 771-779. [CrossRef]

44. Yoshii, F.; Zhao, L.; Wach, R.A.; Nagasawa, N.; Mitomo, H.; Kume, T. Hydrogels of polysaccharide derivatives crosslinked with irradiation at paste-like condition. Nucl. Instrum. Methods Phys. Res. B 2003, 208, 320-324. [CrossRef]

45. Nagasawa, N.; Kimura, A.; Idesaki, A.; Yamada, N.; Koka, M.; Satoh, T.; Ishii, Y.; Taguchi, M. Microfabrication of biocompatible hydrogels by proton beam writing. Nucl. Instrum. Methods B 2017, 409, 102-106. [CrossRef]

46. Miyoshi, H.; Adachi, T. Topography design concept of a tissue engineering scaffold for controlling cell function and fate through actin cytoskeletal modulation. Tissue Eng. Part B Rev. 2014, 20, 609-627. [CrossRef] [PubMed]

47. Murphy, W.L.; McDevitt, T.C.; Engler, A.J. Materials as stem cell regulators. Nat. Mater. 2014, 13, 547-557. [CrossRef] [PubMed]

48. Abbasian, M.; Massoumi, B.; Mohammad-Rezaei, V.; Samadian, H.; Jaymand, M. Scaffolding polymeric biomaterials: Are naturally occurring biological macromolecules more appropriate for tissue engineering? Int. J. Biol. Macromol. 2019, 134, 673-694. [CrossRef]

49. Caliari, S.R.; Burdick, J.A. A practical guide to hydrogels for cell culture. Nat. Methods 2016, 13, 405-414. [CrossRef] [PubMed]

50. Haema, K.; Oyama, T.G.; Kimura, A.; Taguchi, M. Radiation stability and modification of gelatin for biological and medical applications. Radiat. Phys. Chem. 2014, 103, 126-130. [CrossRef]

51. Riedel, S.; Bela, K.; Wisotzki, E.I.; Suckfüll, C.; Zajadacz, J.; Mayr, S.G. Reagent-free mechanical patterning of gelatin surfaces by two-step electron irradiation treatment. Mater. Des. 2018, 153, 80-85. [CrossRef]

52. Tadsen, M.; Friedrich, R.P.; Riedel, S.; Alexiou, C.; Mayr, S.G. Contact guidance by microstructured gelatin hydrogels for prospective tissue engineering applications. ACS Appl. Mater. Interfaces 2019, 11, 7450-7458. [CrossRef]

53. Riedel, S.; Hietschold, P.; Krömmelbein, C.; Kunschmann, T.; Konieczny, R.; Knolle, W.; Mierke, C.T.; Zink, M.; Mayr, S.G. Design of biomimetic collagen matrices by reagent-free electron beam induced crosslinking: Structure-property relationships and cellular response. Mater. Des. 2019, 168, 107606. [CrossRef]

54. Oyama, T.G.; Oyama, K.; Kimura, A.; Yoshida, F.; Ishida, R.; Yamazaki, M.; Miyoshi, H.; Taguchi, M. Elasticity and topography-controlled collagen hydrogels mimicking native cellular milieus. BioRXiv 2019, 706962. [CrossRef]

55. Piruska, A.; Nikcevic, I.; Lee, S.H.; Ahn, C.; Heineman, W.R.; Limbach, P.A.; Seliskar, C.J. The autofluorescence of plastic materials and chips measured under laser irradiation. Lab Chip 2005, 5, 1348-1354. [CrossRef] [PubMed]

56. Whitesides, G.M. The origins and the future of microfluidics. Nature 2006, 442, 368-373. [CrossRef] [PubMed]

57. Zhou, J.; Khodakov, D.A.; Ellis, A.V.; Voelcker, N.H. Surface modification for PDMS-based microfluidic devices. Electrophoresis 2012, 33, 89-104. [CrossRef]

58. Tóth, A.; Bertóti, I.; Blazsó, M.; Bánhegyi, G.; Bognar, A.; Szaplonczay, P. Oxidative damage and recovery of silicone rubber surfaces. I. X-ray photoelectron spectroscopic study. J. Appl. Polym. Sci. 1994, 52, 1293-1307. [CrossRef] 
59. Hillborg, H.; Ankner, J.F.; Gedde, U.W.; Smith, G.D.; Yasuda, H.K.; Wikström, K. Crosslinked polydimethylsiloxane exposed to oxygen plasma studied by neutron reflectometry and other surface specific techniques. Polymer 2000, 41, 6851-6863. [CrossRef]

60. Kim, J.; Chaudhury, M.K.; Owen, M.J.; Orbeck, T. The mechanisms of hydrophobic recovery of polydimethylsiloxane elastomers exposed to partial electrical discharges. J. Colloid. Interface Sci. 2001, 244, 200-207. [CrossRef]

61. Hillborg, H.; Sandelin, M.; Gedde, U.W. Hydrophobic recovery of polydimethylsiloxane after exposure to partial discharges as a function of crosslink density. Polymer 2001, 42, 7349-7362. [CrossRef]

62. Oyama, T.G.; Barba, B.J.D.; Hosaka, Y.; Taguchi, M. Single-step fabrication of polydimethylsiloxane microwell arrays with long-lasting hydrophilic inner surfaces. Appl. Phys. Lett. 2018, 112, 213704. [CrossRef]

63. Kamiya, T.; Suda, T.; Tanaka, R. Submicron microbeam apparatus using a single-ended accelerator with very high voltage stability. Nucl. Instrum. Methods Phys. Res. B 1995, 104, 43-48. [CrossRef]

64. Niita, K.; Sato, T.; Iwase, H.; Nose, H.; Nakashima, H.; Sihver, L. Particle and heavy ion transport code system; PHITS. Radiat. Meas. 2006, 41, 1080-1090. [CrossRef]

(C) 2020 by the authors. Licensee MDPI, Basel, Switzerland. This article is an open access article distributed under the terms and conditions of the Creative Commons Attribution (CC BY) license (http://creativecommons.org/licenses/by/4.0/). 